\title{
Occurrence of Pesticides Associated to Atmospheric Aerosols: Hazard and Cancer Risk Assessments
}

\author{
Aleinnys M. B. Yera, ${ }^{\oplus *, a}$ Madson M. Nascimento, ${ }^{b, c, d}$ Gisele O. da Rocha, ${ }^{b, c, d}$ \\ Jaílson B. de Andrade ${ }^{b, c, e}$ and Pérola C. Vasconcellos ${ }^{(*, a, b}$ \\ ${ }^{a}$ Instituto de Química, Universidade de São Paulo, Av. Prof. Lineu Prestes, 748, \\ 05508-000 São Paulo-SP, Brazil \\ ${ }^{b}$ Instituto Nacional de Ciências e Tecnologias de Energia e Ambiente (INCT), \\ Universidade Federal da Bahia, Campus Ondina, 40110-903 Salvador-BA, Brazil \\ ${ }^{c}$ Centro Interdisciplinar de Energia e Ambiente (CIEnAm), Universidade Federal da Bahia, \\ Campus Ondina, 40110-903 Salvador-BA, Brazil \\ ${ }^{d}$ Instituto de Química, Universidade Federal da Bahia, Campus Ondina, \\ 40110-903 Salvador-BA, Brazil \\ eSENAI-CIMATEC Centro Universitário, 41650-110 Salvador-BA, Brazil
}

\begin{abstract}
Since the 1950s, pesticides have been used in agriculture. The increase in their consumption has been observed in recent years. In this work, it was determined the concentration of pesticides in the atmosphere of São Paulo and Piracicaba cities (sugarcane plantation site) and the hazard quotients and cancer risk caused by inhalation of these compounds were calculated. Twenty-three samples were analyzed and 34 pesticides associated to atmospheric particulate matter (with diameter equal to or less than $2.5\left(\mathrm{PM}_{2.5}\right)$ and $\left.10 \mu \mathrm{m}\left(\mathrm{PM}_{10}\right)\right)$ were investigated by gas chromatograpy-mass spectrometry (GC-MS). Fourteen compounds including organochlorines, organophosphorus, and pyrethroids pesticides, were determined in these samples. The concentrations in the particulate matter ranged from $17 \mathrm{pg} \mathrm{m}^{-3}$ (tebuconazole) in Piracicaba, to $166 \mathrm{pg} \mathrm{m}^{-3}$ (endrin aldehyde) in São Paulo. The highest values of daily inhalation exposure for heptachlor were $9.0 \times 10^{-5} \mathrm{mg} \mathrm{kg}^{-1} \mathrm{day}^{-1}$ at Piracicaba, and $6.5 \times 10^{-5} \mathrm{mg} \mathrm{kg}^{-1} \mathrm{day}^{-1}$ at São Paulo, in both cases registered in infants. The values of the hazard quotients are lower than 1.0, indicating that there is no danger to the exposed population, it is health protective. On the other hand, the cancer risk calculations for heptachlor resulted in values above those recommended by US Environmental Protection Agecy (EPA).
\end{abstract}

Keywords: air pollution, particulate matter, pesticides concentration, risk assessment

\section{Introduction}

The intensive use of pesticides has been leading to the contamination of several environmental compartments, including the atmosphere.

The pesticides distribution in the atmosphere depends on the pesticides physicochemical properties as well as the meteorological conditions of a given study area. In general, the pesticide application can be done by aircraft or land spraying. During the application, from 30 to $50 \%$ of the applied amount can be lost in the atmosphere due to

*e-mail: aleinnysb@usp.br; perola@iq.usp.br spray drift process. Post-application emission is another way of pesticide input in the atmosphere. The properties of molecules that most influence on gas-particle distribution are: vapor pressure, Henry's constant and persistence in the air. However, the vapor pressure is considered the key factor that governs this partitioning. ${ }^{1}$

In the last few years, different types of pesticides have been detected in the atmosphere in rural and urban areas around the world. Villiot et $a .^{2}$ evaluated the concentrations of current used pesticides in the center of Reims (France). A total of 197 samples of particles with diameter equal to or less than ten micrometers $\left(\mathrm{PM}_{10}\right)$ were collected for three years (from 2012 to 2015), and the results showed 28 pesticides detected. ${ }^{2}$ 
Another important information is the risk assessment; it presents the exposure risk of human to different types of pesticides. It can occur via dermal, oral, and inhalation exposures, the latter reaching two or three orders of magnitude smaller than oral exposure. ${ }^{1}$ Even so, the inhalation exposure is important. Viel et al. ${ }^{3}$ associated the presence of organochlorine pesticides in the air with the risk of developing non-Hodgkin lymphoma (NHL) in a population exposed to pesticides. ${ }^{3}$ Due to massive and indiscriminate use of these compounds, the human population, especially infants and children, have presented chronic effects such as the loss of coordination and memory related to Parkinson's and Alzheimer's diseases. ${ }^{4}$ In this way, evaluations of daily inhalation exposure and hazard quotients in all populations are indispensable to assess the risk of the pesticides.

In 2017 the consumption of active products in Brazil reached 540 thousand tons, locating the country as one of the largest consumers of these worldwide. Currently, Brazilian laws ${ }^{5}$ permit the use of 526 different active products, out of which $30 \%$ of them are banned in the European Union and in the United States of America, including: atrazine and acephate. In 2016, the consumption of atrazine reached 29 thousand tons. ${ }^{6}$ The state of São Paulo is the second major consumer of pesticides in Brazil, over 110 thousand tons used in $2016 .^{7}$

The principal objective of this work was to study the pesticides present in inhalable particulate matter collected at two sites of São Paulo State (São Paulo and Piracicaba cities). The results obtained in Piracicaba are the first reference of the determination of pesticides in particulate matter collected in this site. In addition, the found pesticides levels were the basis to calculate the daily inhalation exposure (DIE), the risk assessment, and the cancer risk in all samples.

\section{Experimental}

\section{Site characterization and sampling}

Piracicaba (PRB) is a city located in São Paulo State (Figure S1, Supplementary Information (SI) section). Its population is 400 thousand and it is considered a rural area, with over 94 thousand ha of planted area (approximately $70 \%$ of its total area), with the main crops being sugarcane and oranges. ${ }^{8}$ The most used pesticides in these crops are azoxystrobin, bifenthrin, carbofuran and $\lambda$-cyhalothrin. The study site is localized within the School of Agriculture (University of São Paulo). Sugarcane crops surround the school and most of its area corresponds to experimental crops. $\mathrm{PM}_{10}$ samples $(\mathrm{n}=8)$ were collected in PRB in
October 2008, about $3 \mathrm{~m}$ above the ground level. The result obtained in these samples will allow us to perform a brief initial characterization of the pesticides behavior in the atmosphere of the rural site.

The other city studied was São Paulo (SPA). The metropolis is the capital of São Paulo State and most populous city in Brazil, with over 12 million inhabitants (Figure S2, SI section). SPA have a strong industrial character. Agriculture is not an important sector of its economy, only $7 \%$ (11 thousand ha) of its total area is dedicated to this activity, being beans and cassava its principal crops. ${ }^{9}$ Pesticides as azoxystrobin, bifenthrin, carbofuran, $\lambda$-cyhalothrin, and permethrin used in beans and cassava crops, gardens, and the domestic pest control are the most consumed..$^{10}$

Samples of particles with diameter equal to or less than 2.5 micrometers $\left(\mathrm{PM}_{2.5}\right)$ were collected about $20 \mathrm{~m}$ above the ground level, in the rooftop of a building (Institute of Astronomy, Geophysics and Atmospheric Sciences, University of São Paulo). The location is inside a green area and approximately $2 \mathrm{~km}$ away from an important highway. $\mathrm{PM}_{2.5}$ samples $(\mathrm{n}=15)$ were collected in August 2017, with the aim of studying pesticides behavior in the atmosphere of an urban site.

The samples in both sites were collected using a highvolume sampler at flow rate $1.13 \mathrm{~m}^{3} \mathrm{~min}^{-1}$, with 2.5 and $10 \mu \mathrm{m}$ size selective inlets (Thermo Andersen, USA). The sampling time was $24 \mathrm{~h}$ for both sites. Prior to sampling, quartz fibre filters $(20 \times 25 \mathrm{~cm}$, Millipore, USA) were baked in a muffle furnace at $650{ }^{\circ} \mathrm{C}$ for $6 \mathrm{~h}$ to eliminate organics residues. In addition, filters were equilibrated at room temperature and weighed in a microbalance, before and after the sampling, in order to estimate the concentration of particulate matter (PM). After sampling and weighing, the filters were wrapped in aluminium foil and stored in a refrigerator at $5{ }^{\circ} \mathrm{C}$ until chemical analyses were performed.

The meteorological data (ambient temperature, precipitation, and wind speed) were collected from the database of the agrometeorological station at School of Agriculture (LEB, ESALQ, USP) for the campaigns in PRB. ${ }^{11}$ The meteorological data for SPA were collected from the climatological bulletin of the meteorological station at Institute of Astronomy, Geophysics and Atmospheric Sciences (IAG, USP). ${ }^{12}$

\section{Reagent and chemicals}

Environmental Protection Agency (EPA) organochlorine mix standard with $\alpha$-hexachlorocyclohexane $(\alpha-\mathrm{HCH})$, $\gamma-\mathrm{HCH}, \beta-\mathrm{HCH}$, heptachlor, $\delta$-HCH aldrin, heptachlor- 
epoxide, $\alpha$-endosulfan, dichloro-diphenyldichloroethylene (4, 4' - DDE), dieldrin, endrin, dichlorodiphenyldichloroethane (4,4'-DDD), $\beta$-endosulfan, dichloro-diphenyltrichloroethane (4,4'-DDT), endrin aldehyde and methoxychlor were acquired from SigmaAldrich (St. Louis, USA). Malathion, parathion, sulfotep, fenthion, disulfoton, demeton-o, and bifenthrin standards were purchased from AccuStandard (New Haven, USA). TCMX (2,4,5,6-tetrachloro- $m$-xylene) and PCB103 $\left(2,2^{\prime}, 4,5^{\prime}, 6\right.$-pentachlorobiphenyl) were used as surrogate standards and were purchased from Ultra Scientific (North Kingstown, USA). Acetonitrile were purchased from Merck (Darmstadt, Germany). Ethyl acetate was supplied by Macron (Center Valley, USA). All organic solvents used were spectroscopic and high-performance liquid chromatography (HPLC) grade.

A mix working solution containing all pesticides was prepared in ethyl acetate. Matrix-matching calibration curves were prepared for each compound, adding varied volumes of the mix working solution in extracts of blank filters, as described in Nascimento et al. ${ }^{13}$ Each calibration curve is composed of seven levels of concentrations 0.5 , $1.0,2.5,4.5,6.5,8.5,10.5 \mathrm{ng} \mathrm{mL}^{-1} .^{13}$

\section{Extraction and sample analysis}

The pesticides determination was carried out according to method previously published elsewhere. ${ }^{13}$ Briefly, a $4.15 \mathrm{~cm}^{2}$ filter section was cut and transferred to a microextraction device with borosilicate glass chamber (Whatman Mini-UniPrep G2, USA). Then, $10 \mu \mathrm{L}$ of the surrogate standard TCMX and PCB103 with concentrations of $6.5 \mathrm{ng} \mathrm{mL} \mathrm{m}^{-1}$ were added to the particles in the filter. After surrogate standard adsorption $(2 \mathrm{~h}), 500 \mu \mathrm{L}$ of a binary solvent mixture composed of ethyl acetate/acetonitrile mixture (30:70) was added and the whole system was sonicated during $23 \mathrm{~min}$ at $39^{\circ} \mathrm{C}$ using an ultrasonic bath (Symphony-VRW, Radnor, Pennsylvania, USA). Then, the extract was instantly filtered in the same device and injected into gas chromatograph coupled to mass spectrometer (GC-MS).

\section{Analytical performance and identification criteria}

The analytical performance of the method was assessed considering the following figures-of-merit: linear range, linearity, limit of detection (LOD), limit of quantification (LOQ), instrumental precision (by mean of intraday and interday precision). ${ }^{13}$ All calibration curves presented suitable determination coefficient values ranging from $0.9903(\beta-\mathrm{HCH})$ to $0.9985(\delta-\mathrm{HCH})$. The relative standard deviation (RSD, \%) values for intraday precision ranged from 0.19 (permethrin II) to $3.4 \%$ (heptachlor epoxide). LOD values ranged from $0.14(\delta-\mathrm{HCH})$ to $0.44 \mathrm{ng} \mathrm{mL}^{-1}$ (permethrin II) and LOQ values ranged from 0.63 (diazinon) to $1.5 \mathrm{ng} \mathrm{mL}^{-1}$ (permethrin II) (Table $\mathrm{S} 1$, SI section). The method performance for organochlorine pesticides was assessed by using surrogate standards TCMX and PCB103. These were added to blank samples, solvent blanks and samples before extraction. The average recoveries of TCMX and PCB103 in all samples ranged from 90 to $144 \%$ with RSD lower than $14 \%$.

The pesticides identification and confirmation by GC-MS were performed according to criteria established by SANCO: ${ }^{14}(i)$ at least three diagnostic ions; (ii) retention time of the analyte in the sample should be similar to standard within $\pm 0.20 \mathrm{~min}$; (iii) signal-to-noise $(\mathrm{S} / \mathrm{N})$ of the least intense ion $>3: 1 .{ }^{14}$ The qualifier ions used to pesticide identification are shown in the Table S1 (SI section).

\section{Quality assurance/quality control}

All non-volumetric glassware, including the borosilicate glass chamber, was cleaned with organic solvents (acetone and hexane) and then, baked in a muffle furnace at $450^{\circ} \mathrm{C}$ for $4 \mathrm{~h}$. After cleaning procedure, glassware blanks were tested, and no interfering peaks were observed. The instrument, reagent, method and field blanks were evaluated. The instrument blank consisted of GC-MS carrier gas analysis in order to detect the presence of interfering compounds and level of instrumental noise. The reagent blank was evaluated injecting extraction blanks containing only the extraction solvent (ethyl acetate/acetonitrile mixture, 30:70) into GC-MS. The method blank was assessed by extracting and further analysis of blank filters (without particles). The field blank was assessed by analyzing a non-sampled filter. If any interfering peak are detected in the same retention time of target pesticides, then the peak was discounted of original sample.

\section{Inhalation exposure and risks assessment}

The inhalation is an important source of atmospheric pesticides exposure. Following the methodology and the equations proposed by Coscollà and Yusà, ${ }^{1}$ the daily inhalation exposure (DIE), the risk assessment and the cancer risk for three different populations: infants (6 months to 1.5 years), children (1.5 to 6 years) and adults (>12 years), were calculated. ${ }^{1}$

The DIE $\left(\mathrm{mg} \mathrm{kg}^{-1} \mathrm{day}^{-1}\right)$ refers to the amount of pesticides to which a given population is daily exposed. It was determined using the equation 1 . 
$\mathrm{DIE}=\frac{\Sigma \mathrm{C} \times \mathrm{IRinh} \times \mathrm{ED}}{\mathrm{BW}}$

where $\mathrm{C}\left(\mathrm{mg} \mathrm{m}^{-3}\right)$ is the total concentration ( $\mathrm{gas}+$ particulate phase) of each pesticide; IRinh $\left(\mathrm{m}^{3} \mathrm{~h}^{-1}\right)$ is the inhalation rate per hour, the IRinh applied was $8 \mathrm{~m}^{3}$ day $^{-1}$ for infants, $10 \mathrm{~m}^{3}$ day $^{-1}$ for children and $20 \mathrm{~m}^{3}$ day $^{-1}$ for adults; $\mathrm{ED}$ is the exposure duration (h), for the three groups of individuals were considered $24 \mathrm{~h}$ of exposure; $\mathrm{BW}$ is the body weight $(\mathrm{kg})$, which was considered to be $10 \mathrm{~kg}$ for infants, $15 \mathrm{~kg}$ for children and $70 \mathrm{~kg}$ for adults.

The risk assessment was calculated using the hazard quotient (HQ) as a descriptor of the risk (equation 2).

$\mathrm{HQ}=\frac{\mathrm{DIE}}{\mathrm{HBRV}}$

where HBRV is the health based reference values and it was calculated using the AOEL, defined as the acceptable operator exposure levels. ${ }^{1} \mathrm{HQ}$ values higher than 1 mean that the populations are more exposed to the pesticides than the operator (person who works directly with the formulation).

The cancer risk was calculated by the equation 3 . It refers to compounds classified by the Environmental Protection Agency (EPA) as "likely to be carcinogenic to humans" and/or "possible human carcinogen" (diazinon, heptachlor, 4,4'-DDE, tebuconazole, permethrin I and permethrin II). ${ }^{15}$

Cancer risk $=\mathrm{DIE} \times \mathrm{PF}$

Potency factor (PF) is the factor that estimates the potency of the carcinogenicity. Lee et al. ${ }^{16}$ presented a table with these values for some pesticides. In general, these values range from $10^{-3}$ to $10^{-1} .{ }^{16}$ Some values of PF for specific pesticides were not found, and 0.1 was assumed for all pesticides (situation with major potency).

\section{Total concentration $(\mathrm{C})$}

$\mathrm{C}$ is the sum of the concentrations in both gaseous and particulate phases. In the present study, only pesticides in particulate matter were determined. However, the corresponding gas phase pesticides concentrations were estimated using the octanol-air model $\left(\mathrm{K}_{\mathrm{oa}}\right)$ proposed by Harner and Bidleman ${ }^{17}$ (SI section).

\section{Results and Discussion}

Concentrations of pesticides in the particulate matter

Twenty pesticides were detected and 14 were quantified, considering both sampling sites. For PRB samples, the compounds with the highest detection frequency (greater than 50\%), taking into account values above the LOD, were heptachlor and ethion, $\beta$-endosulfan, bifenthrin, permethrin I and II, $\lambda$-cyhalothrin and demeton-o. For SPA samples, the pesticides with the highest detection frequencies were permethrin I and II, diazinon, $\beta$-endosulfan, bifenthrin and ethion (Tables S3 and S4, SI section). The concentrations ranged from $15 \mathrm{pg} \mathrm{m}^{-3}$ for tebuconazole to $160 \mathrm{pg} \mathrm{m}^{-3}$ for ethion in PRB and from $15 \mathrm{pg} \mathrm{m}^{-3}$ (diazinon) to $166 \mathrm{pg} \mathrm{m}^{-3}$ (endrin aldehyde) in SPA. Figures 1 and 2 show the range and average values of the concentration of pesticides for PRB and SPA, respectively.

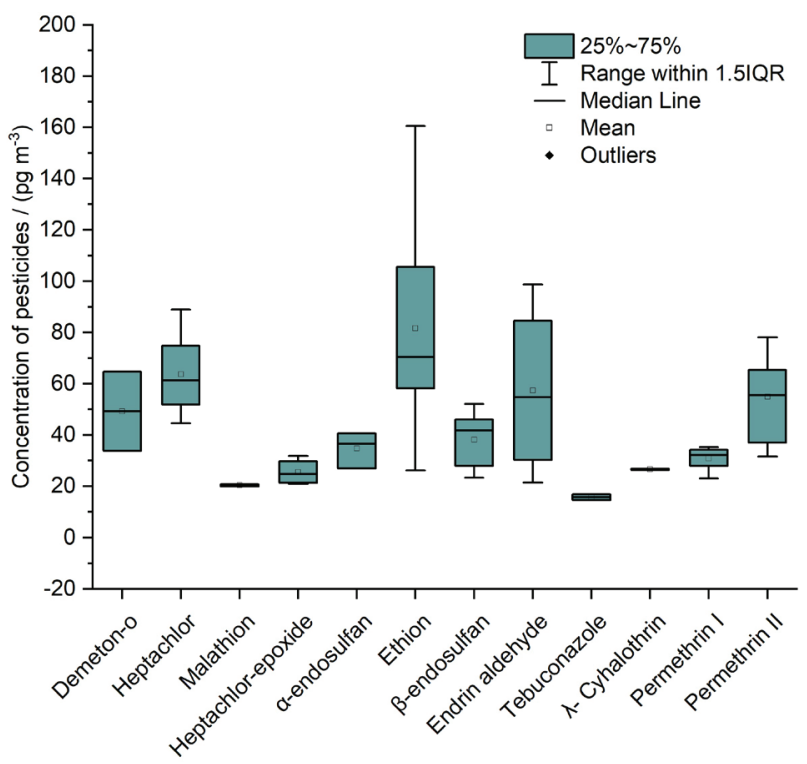

Figure 1. Concentrations of pesticides in the particulate phase at Piracicaba (PRB).

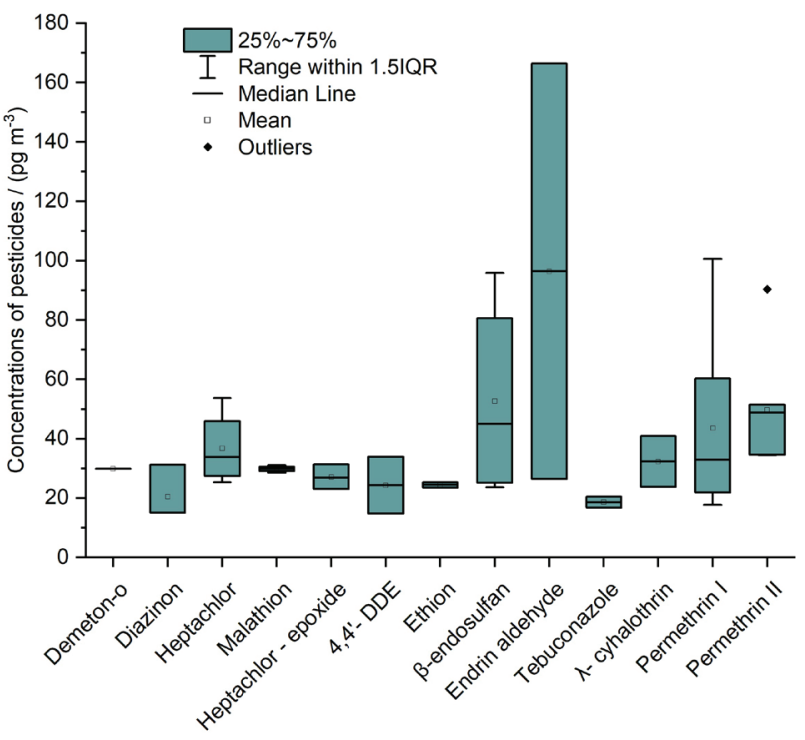

Figure 2. Concentrations of pesticides in the particulate phase at São Paulo (SPA). 
Bifenthrin and permethrin are insecticides of the pyrethroids group, and they are widely used in Brazil for the application in plantations such as sugarcane, corn, coffee, soybean and bean. ${ }^{5}$ These five leguminous species are among the ten most planted in São Paulo State, ${ }^{7}$ which explains their high detection frequencies.

Bifenthrin is predominant in the particulate phase due to its low vapor pressure $\left(1.8 \times 10^{-5} \mathrm{~Pa}\right),{ }^{18}$ which would explain the high detection frequency. Despite the fact, its concentrations were below to LOQ in both sites. Concentrations of bifenthrin over $83 \mathrm{pg} \mathrm{m}^{-3}$ and detection frequency of $47 \%$ were found in $\mathrm{PM}_{10}$ samples in an area of Valencia Region, Spain. ${ }^{19}$

Endosulfan ( $\alpha$ and $\beta$ ) were largely used in Brazil to control insects populations in sugarcane, cocoa, coffee, soybean, and cotton plantations. It was only totally banned in Brazil in 2013. ${ }^{5}$ The maximum concentration found for $\beta$-endosulfan in SPA was $96 \mathrm{pg} \mathrm{m}^{-3}$ and in PRB was $52 \mathrm{pg} \mathrm{m}^{-3}$. The $\alpha$-endosulfan was not found in SPA samples, while its average concentrations in the PRB samples are over $35 \mathrm{pg} \mathrm{m}^{-3}$ (Figures 1 and 2).

Compounds like $\alpha$ - and $\beta$-endosulfan present vapor pressures (0.0044 and $0.0040 \mathrm{~Pa}$, respectively) suggesting that they are mostly in the gas phase. ${ }^{20}$ Few works determined the concentrations of these compounds only in the particulate phase. Chrysikou et al..$^{21}$ and Coscollà et al..$^{22}$ did not detect in $\mathrm{PM}_{2.5}$ collected in rural and urban cities in Europe. However, values of $29 \mathrm{pg} \mathrm{m}^{-3}$ are reported in the gas phase in a remote area in southern Brazil. ${ }^{23}$

Concentrations of $\alpha$-endosulfan are generally greater than $\beta$-endosulfan because the latter is more unstable, it is more prone to undergo degradation or transformation into its other isomer. In addition, the losses due to wet depositions are greater for $\beta$-endosulfan because it has a higher solubility. ${ }^{23}$

More than $95 \%$ of the endosulfan formulation corresponds to its $\alpha$ and $\beta$ isomers. ${ }^{20}$ The $\alpha: \beta$ ratio varies with the manufacturer but it is generally in the range of $2: 1$ to $7: 3$. Elevated $\alpha: \beta$ ratio represents an aged signature scenario for these pesticides. ${ }^{23}$ In this work, the ratio for PRB, considering the average of all the samples ( $35 \mathrm{pg} \mathrm{m}^{-3}$ for $\alpha$-endosulfan and $38 \mathrm{pg} \mathrm{m}^{-3}$ for $\beta$-endosulfan), was 0.9 , which suggests a recent application of this pesticide nearby the sampling area.

Heptachlor is highly toxic to human health, banned in the countries of the European Union. In Brazil, up to 2007, its use was only allowed for wood preservation. But since 2016, it is prohibited for any use in Brazil. ${ }^{5}$ In PRB, it was detected in all samples, and in a low frequency (40\%) as well as in the samples of SPA, which were collected in 2017 (after its total prohibition). This pesticide is intensely used for sugarcane pests' control, a predominant crop in PRB.$^{10}$ In this site, the average concentration was $64 \mathrm{pg} \mathrm{m}^{-3}$. The highest and average concentrations found in SPA were 54 and $37 \mathrm{pg} \mathrm{m}^{-3}$, respectively. Wang et al..$^{24}$ found average concentration of $34.5 \mathrm{pg} \mathrm{m}^{-3}$ in the summer of Vietnam. Heptachlor is rapidly converted to heptachlorepoxide mainly by biodegradation. Therefore, when the concentrations of heptachlor are greater than heptachlorepoxide, it can indicate a recent use of the product according to Secretary of Health of São Paulo State report (2003) ${ }^{25}$ In this work, the average heptachlor concentrations $\left(64 \mathrm{pg} \mathrm{m}^{-3}\right.$ in PRB and $37 \mathrm{pg} \mathrm{m}^{-3}$ in SPA) exceeds the atmospheric heptachlor-epoxide levels (26 $\mathrm{pg} \mathrm{m}^{-3}$ in PRB and $27 \mathrm{pg} \mathrm{m}^{-3}$ in SPA) (Figures 1 and 2).

Ethion was the compound that presented the highest concentrations in PRB and was found in $100 \%$ of the samples, with average concentration of $82 \mathrm{pg} \mathrm{m}^{-3}$ and maximum concentration of $161 \mathrm{pg} \mathrm{m}^{-3}$ (Figure 1). For the samples collected in SPA, ethion was only detected in 53\% of the samples, and the highest concentrations were over $25 \mathrm{pg} \mathrm{m}^{-3}$. In turn, diazinon is used in fruits and vegetables crops and in the insects control in ornamental plants. ${ }^{10}$ In PRB it was not detected, while in SPA the detection frequency was at $93 \%$ of the samples and the maximum concentration reached $31 \mathrm{pg} \mathrm{m}^{-3}$. In other urban areas, as in the case of Valencia (Spain), average concentrations of diazinon over $30 \mathrm{pg} \mathrm{m}^{-3}$ are reported, ${ }^{26}$ a result similar to that determined in this work.

Even though 34 pesticides are investigated in the samples collected in SPA and PRB, only 14 pesticides were found in most of the samples of both sites. In PRB, eight pesticides presented a high frequency of detection, while in SPA only six of them presented a high frequency of detection (Tables S3 and S4, SI section). For PRB, the high pesticides frequencies and concentrations may be due to the wide use of a large amount of pesticides in the area nearby the sampling site.

Figure 3 shows the variation of the sum of de concentrations of pesticides $\left(\Sigma \mathrm{C}_{\text {pesticides }}\right)$ in the particulate phase and some meteorological parameters at PRB site. The highest value found for $\Sigma \mathrm{C}_{\text {pesticides }}$ was $484 \mathrm{pg} \mathrm{m}^{-3}$, while the lowest value was $69 \mathrm{pg} \mathrm{m}^{-3}$. Concentrations of $\mathrm{PM}_{10}$ ranged from 26 to $120 \mu \mathrm{g} \mathrm{m}^{-3} .{ }^{27}$ Days that presented high and low values of concentrations of $\mathrm{PM}_{10}$ presented similar values of $\Sigma \mathrm{C}_{\text {pesticides }}$. The rainfall occurred in only 2 days of sampling, in which the $\Sigma \mathrm{C}_{\text {pesticides }}$ were 379 and $206 \mathrm{pg} \mathrm{m}^{-3}$, respectively. The sample collected in the warmest day (PRB 7, $27^{\circ} \mathrm{C}$ ) and with highest wind speed $\left(12 \mathrm{~km} \mathrm{~h}^{-1}\right)$ presented the lower value of $\Sigma \mathrm{C}_{\text {pesticides }}\left(69 \mathrm{pg} \mathrm{m}^{-3}\right)$.

For SPA samples, the lowest $\Sigma \mathrm{C}_{\text {pesticides }}$ was over $31 \mathrm{pg} \mathrm{m}^{-3}$ and the highest was $372 \mathrm{pg} \mathrm{m}^{-3}$. Concentrations of $\mathrm{PM}_{2.5}$ ranged from 6 to $79 \mu \mathrm{g} \mathrm{m}^{-3}$. On the sampling days, 


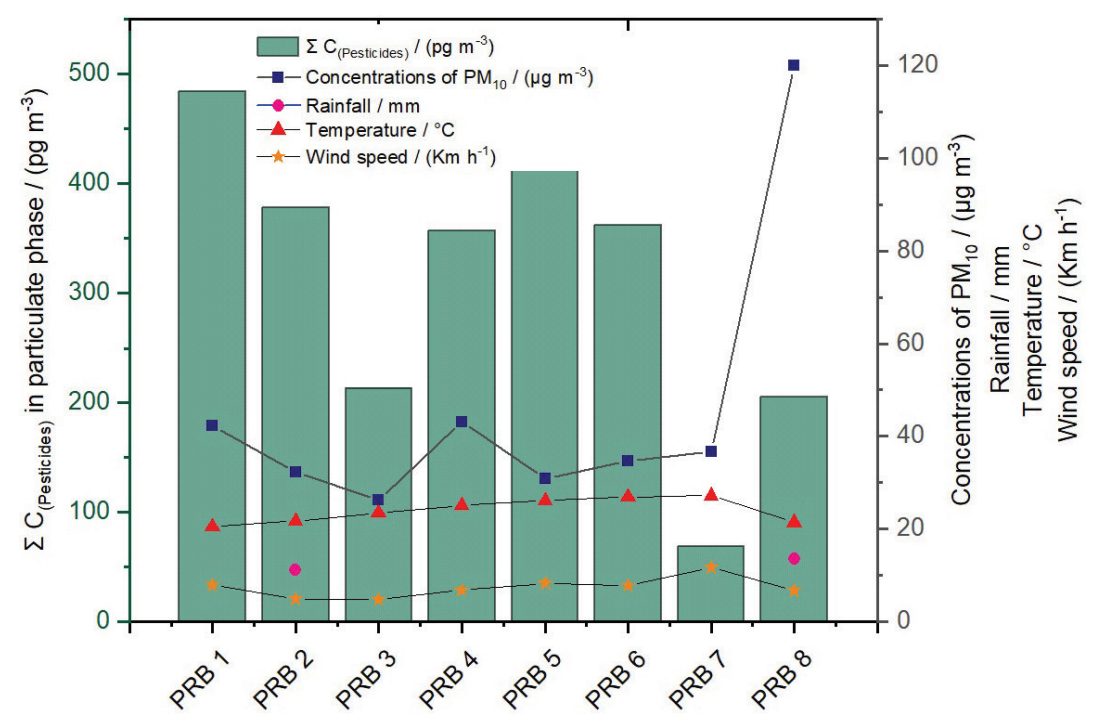

Figure 3. Sum of the concentrations of all pesticides $\left(\Sigma \mathrm{C}_{\text {pesticides }}\right)$ present in particulate phase for each sample and meteorological parameter at PRB site. $\Sigma \mathrm{C}_{\text {pesticides }}$ are represented by green bars (left axis), whereas concentrations of $\mathrm{PM}_{10}$, rainfall, temperature and wind speed are represented as line and point (right axis).

the temperature ranged from 14 to $21^{\circ} \mathrm{C}$. The rainfall, nevertheless, occurred in 6 sampling days, reaching the maximum of $32 \mathrm{~mm}$ (SPA 75, Figure 4). The sample with the highest $\Sigma \mathrm{C}_{\text {pesticides }}$ was SPA $68\left(372 \mathrm{pg} \mathrm{m}^{-3}\right)$, which also presented high concentration of particulate matter $\mathrm{PM}_{2.5}$ $\left(30 \mathrm{\mu g} \mathrm{m}^{-3}\right)$, the highest ambient temperature $\left(21^{\circ} \mathrm{C}\right)$ and no rainfall episode; it is expected that pollutants are normally eliminated from the atmosphere by wet deposition. In this day, pesticides input in the atmosphere was maximized since the only atmospheric removal mechanisms were dry deposition and degradation.

Pearson analysis for the PRB samples showed the correlations between the concentrations of pesticides in the particulate phase, concentrations of $\mathrm{PM}_{10}$ and meteorological parameter. In general, the correlations between pesticides depends on the chemical class (organochlorines, organophosphorus, pyrethroids and triazole) and application frequency. The greatest correlation found (0.95) was for demeton-o and malathion, both organophosphorus pesticides. They are used as insecticide in sugarcane crops and have the same mechanism of action, so their atmospheric reactions or degradation could be similar. High correlation was also found between permethrin I and permethrin II. These isomers are the components of the commercial formulation and have the same chemical behavior in the atmosphere.

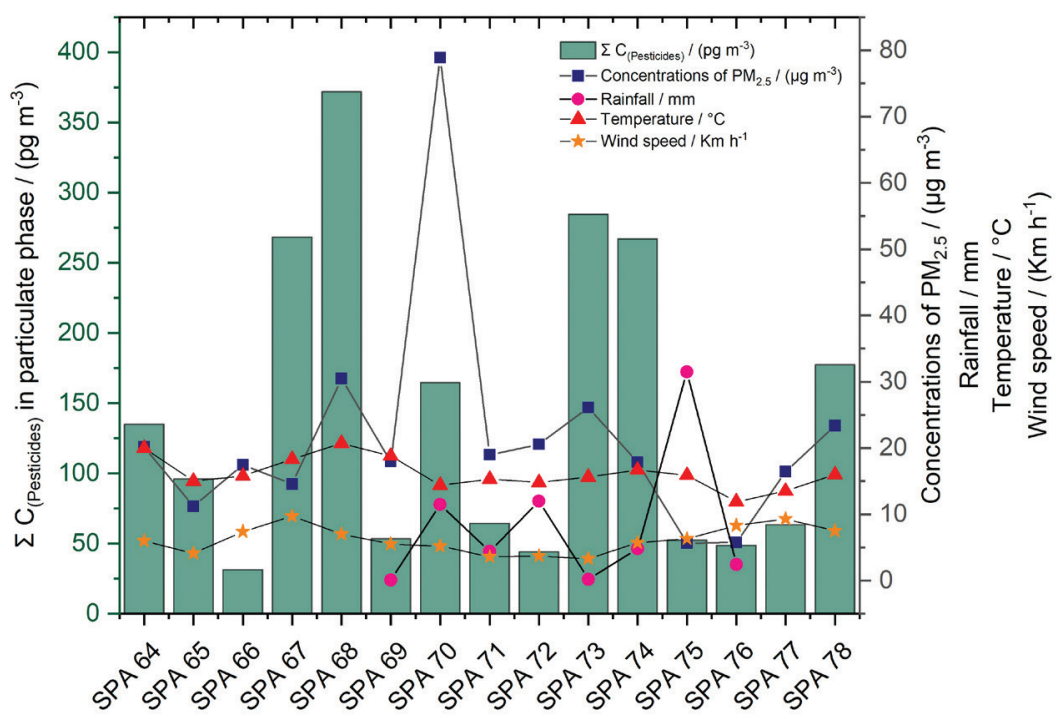

Figure 4. Sum of the concentrations of all pesticides $\left(\Sigma \mathrm{C}_{\text {pesticides }}\right)$ present in particulate phase for each sample and meteorological parameter at SPA site. $\Sigma \mathrm{C}_{\text {pesticides }}$ are represented by green bars (left axis), whereas concentrations of $\mathrm{PM}_{10}$, rainfall, temperature and wind speed are represented as line and point (right axis). 
Negative correlation was found for heptachlor and heptachlor epoxide (-0.74). It is expected since heptachlor epoxide is the main product of the heptachlor degradation. ${ }^{25}$ It is reasonable, that as the concentration of heptachlor decreases, the concentration of heptachlor epoxide deceases. This hypothesis is also demonstrated with the fact that, for the compounds that present high correlation with heptachlor (demeton-o: 0.75, malathion: $0.84, \alpha$-endosulfan: 0.83 and endrin aldehyde: 0.74 ), these correlations are negative with heptachlor epoxide (demeton-o: -0.53 , malathion: -0.56 , $\alpha$-endosulfan: -0.74 and endrin aldehyde: -0.57$)$. Similarly, the $\beta$-endosulfan presented positive correlation with heptachlor epoxide $(0.60)$ and negative with heptachlor $(-0.58)$.

$\alpha$-Endosulfan and $\beta$-endosulfan are the components of the commercial endosulfan formulation, being $\alpha$-endosulfan found in higher concentration than its isomer. $\alpha$-Endosulfan can be transformed to $\beta$-endosulfan in the environment, ${ }^{23}$ which could explain the negative correlation found for these compounds $(-0.62)$.

Low correlations were found between concentrations of pesticides and meteorological parameters. The only pesticide that presented a moderate negative correlation was ethion with wind speed (-0.69). A general analysis of the correlations between the individual pesticides and the meteorological conditions in this rural area indicates that the concentrations variation depends more on the physical and chemical properties of the compounds than on meteorological conditions.

For the SPA samples, the Pearson analysis does not provide much information. The correlations between pesticides concentration are generally low. The pesticide with the highest number of positive and high correlation was diazinon (4,4'-DDE: 0.72 , ethion: 0.83 , and endrin aldehyde: 0.80 ). These correlations are difficult to explain since these pesticides do not have similar physical and chemical properties. Regarding the temperature, moderate positive correlations were found with diazinon (0.60) and ethion (0.71). The increase in temperature favors the compounds volatilization from the ground, plants and other surfaces. ${ }^{28}$

\section{Risk assessment}

The fraction of the pesticides in the particulate phase $(\Phi)$ was calculated to estimate the concentration in the gaseous phase and the total concentration $\left(\mathrm{C}_{\text {total }}\right)$ of the pesticides. Compounds with vapor pressure lower than $10^{-5}$ can be mostly found in the particulate phase; between $10^{-5}$ to $10^{-2}$ can be distributed in both phases and higher than $10^{-2}$ can be mostly found in the gaseous phase. ${ }^{26}$ Following this approach and comparing the vapor pressure of these pesticides, it was observed that compounds like demeton-o, diazinon, heptachlor, malathion, heptachlor-epoxide, 4,4'-DDE, $\alpha$-endosulfan, $\beta$-endosulfan and endrin aldehyde, are prone to be found in the gaseous phase. Ethion, permethrin I and permethrin II are distributed in both phases. Tebuconazole and $\lambda$-cyhalothrin are predominantly found in the particulate phase (Tables S5 and S6, SI section).

For compounds with very small $\Phi\left(10^{-4}\right.$ to $\left.10^{-2}\right)$ the total concentrations were higher than compounds with high $\Phi$ (Tables S5 and S6, SI section). This is because the most part of these compounds is in the gaseous phase, so that, practically the whole amount of them was in the gas phase and they were estimated through the $\mathrm{K}_{\mathrm{oa}}$ model.

DIE values for three different population groups (adults, children and infants) were calculated for both sampling sites considering the average (Table S7, SI section) and the maximum concentrations (Table 1). The DIE values range from $5 \times 10^{-9} \mathrm{mg} \mathrm{kg}^{-1} \mathrm{day}^{-1}$ for tebuconazole in adults to $1 \times 10^{-4} \mathrm{mg} \mathrm{kg}^{-1}$ day $^{-1}$ for heptachlor in infant at PRB, while in SPA, the values ranged from $6 \times 10^{-9} \mathrm{mg} \mathrm{kg}^{-1}$ day $^{-1}$ for tebuconazole in adults to $9 \times 10^{-5} \mathrm{mg} \mathrm{kg}^{-1}$ day $^{-1}$ for heptachlor in infants. In general, it is expected that the highest DIE values are attributed to the most vulnerable population (infants) because they have lower body weight. ${ }^{1}$

For demeton-o and malathion the DIE maximum values in infants at PRB were $7 \times 10^{-6}$ and $1 \times 10^{-6} \mathrm{mg} \mathrm{kg}^{-1}$ day $^{-1}$, respectively, and $4 \times 10^{-6}$ and $9 \times 10^{-6} \mathrm{mg} \mathrm{kg}^{-1}$ day $^{-1}$ at SPA. These results are slightly higher than that reported by Nascimento et al. ${ }^{13}$ in Salvador, northeastern Brazil, $4 \times 10^{-8}$ and $5 \times 10^{-8} \mathrm{mg} \mathrm{kg}^{-1} \mathrm{day}^{-1}$ in infants for demeton-o and malathion, respectively. ${ }^{13}$ Low DIE were also found for malathion in Valencia region in different years, $2 \times 10^{-7} \mathrm{mg} \mathrm{kg}^{-1}$ day $^{-1}$ in 2010 and $6 \times 10^{-7} \mathrm{mg} \mathrm{kg}^{-1}$ day $^{-1}$ in $2014 .{ }^{26,29}$

The hazard quotient, $\mathrm{HQ}_{\mathrm{AOEL}}$, gives us a measure of how close the daily inhalation value is to the highest value that an operator can be exposed. Values greater than 1 indicate a risk to the human health. ${ }^{1}$ Table 1 compares the results obtained of $\mathrm{HQ}_{\mathrm{AOEL}}$ for the maximum concentrations of pesticides in adults, children, and infants; Table S7 (SI section) shows the $\mathrm{HQ}_{\mathrm{AOEL}}$ values for the average concentrations of pesticides.

In PRB the highest values of $\mathrm{HQ}_{\mathrm{AOEL}}$ were found in infants ( $\alpha$-endosulfan: $4 \times 10^{-3}$, $\beta$-endosulfan: $1 \times 10^{-3}$, and ethion: $3 \times 10^{-4}$ ), while for SPA the highest values were for diazinon: $7 \times 10^{-3}$, $\beta$-endosulfan: $3 \times 10^{-3}$ and malathion: $3 \times 10^{-4}$. Values reported ${ }^{29}$ in Valencia for tebuconazole $\left(6 \times 10^{-3}\right)$ in infants were higher than the values found for PRB $\left(5 \times 10^{-7}\right)$ and for SPA $\left(6 \times 10^{-7}\right)$. All the values found in this work are below 1.0, indicating that there is no risk to 
Table 1. Maximum concentrations in particulate and gaseous phase $\left(\mathrm{C}_{\max }\right)$, daily inhalation exposure (DIE) and hazard quotient $\left(\mathrm{HQ}_{\mathrm{AOEL}}\right)$ of the most detected pesticides in both sampling sites for infants, children and adults

\begin{tabular}{|c|c|c|c|c|c|c|c|c|c|c|c|c|c|c|}
\hline \multirow{3}{*}{ Pesticide } & \multicolumn{2}{|c|}{$\mathrm{C}_{\max } /\left(\mathrm{pg} \mathrm{m}^{-3}\right)$} & \multicolumn{4}{|c|}{ Infants } & \multicolumn{4}{|c|}{ Children } & \multicolumn{4}{|c|}{ Adults } \\
\hline & \multirow[b]{2}{*}{ PRB } & \multirow[b]{2}{*}{ SPA } & \multicolumn{2}{|l|}{ PRB } & \multicolumn{2}{|l|}{ SPA } & \multicolumn{2}{|l|}{ PRB } & \multicolumn{2}{|l|}{ SPA } & \multicolumn{2}{|c|}{ PRB } & \multicolumn{2}{|l|}{ SPA } \\
\hline & & & $\begin{array}{c}\text { DIE / } \\
\left(\mathrm{mg} \mathrm{kg}^{-1} \mathrm{day}^{-1}\right)\end{array}$ & $\mathrm{HQ}_{\mathrm{AOEL}}$ & $\begin{array}{c}\mathrm{DIE} / \\
\left(\mathrm{mg} \mathrm{kg}^{-1} \mathrm{day}^{-1}\right)\end{array}$ & ) $\mathrm{HQ}_{\mathrm{AOEL}}$ & $\begin{array}{c}\text { DIE / } \\
\left(\mathrm{mg} \mathrm{kg}^{-1} \mathrm{day}^{-1}\right)\end{array}$ & $\left.{ }_{1}\right) Q_{\text {AOEL }}$ & $\begin{array}{c}\text { DIE / } \\
\left(\mathrm{mg} \mathrm{kg}^{-1} \mathrm{day}^{-1}\right)\end{array}$ & 1) $\mathrm{HQ}_{\mathrm{AOEL}}$ & $\begin{array}{c}\text { DIE / } \\
\left(\mathrm{mg} \mathrm{kg}^{-1} \mathrm{day}^{-1}\right.\end{array}$ & 1) $\mathrm{HQ}_{\mathrm{AOEL}}$ & $\begin{array}{c}\text { DIE / } \\
\left(\mathrm{mg} \mathrm{kg}^{-1} \text { day }^{-1}\right)\end{array}$ & ${ }_{1}^{1)} \mathrm{HQ}_{\mathrm{AOEL}}$ \\
\hline Demeton-o & 8262 & 5090 & $7 \times 10^{-6}$ & - & $4 \times 10^{-6}$ & - & $6 \times 10^{-6}$ & - & $3 \times 10^{-6}$ & - & $2 \times 10^{-6}$ & - & $2 \times 10^{-6}$ & - \\
\hline Diazinon & - & 1711 & & - & $1 \times 10^{-6}$ & $7 \times 10^{-3}$ & & - & $1 \times 10^{-6}$ & $6 \times 10^{-3}$ & - & - & $5 \times 10^{-7}$ & $2 \times 10^{-3}$ \\
\hline Heptachlor & 175299 & 110000 & $1 \times 10^{-4}$ & - & $9 \times 10^{-5}$ & - & $1 \times 10^{-4}$ & - & $7 \times 10^{-5}$ & - & $5 \times 10^{-5}$ & - & $3 \times 10^{-5}$ & - \\
\hline Malathion & 1700 & 10600 & $1 \times 10^{-6}$ & $5 \times 10^{-5}$ & $9 \times 10^{-6}$ & $3 \times 10^{-4}$ & $2 \times 10^{-6}$ & $4 \times 10^{-5}$ & $7 \times 10^{-6}$ & $2 \times 10^{-4}$ & $5 \times 10^{-7}$ & $9 \times 10^{-6}$ & $3 \times 10^{-6}$ & $1 \times 10^{-4}$ \\
\hline Heptachlor-epoxide & 11200 & 21000 & $9 \times 10^{-6}$ & - & $2 \times 10^{-5}$ & - & $8 \times 10^{-6}$ & - & $1 \times 10^{-5}$ & - & $3 \times 10^{-6}$ & - & $6 \times 10^{-6}$ & - \\
\hline$\alpha$-Endosulfan & 8790 & - & $7 \times 10^{-6}$ & $4 \times 10^{-3}$ & & - & $6 \times 10^{-6}$ & $3 \times 10^{-3}$ & - & - & $3 \times 10^{-6}$ & $7 \times 10^{-4}$ & - & - \\
\hline 4,4'-DDE & - & 559 & & - & $5 \times 10^{-7}$ & - & & - & $4 \times 10^{-7}$ & - & - & - & $2 \times 10^{-7}$ & - \\
\hline Ethion & 616 & 115 & $5 \times 10^{-7}$ & $3 \times 10^{-4}$ & $9 \times 10^{-8}$ & $6 \times 10^{-5}$ & $4 \times 10^{-7}$ & $3 \times 10^{-4}$ & $8 \times 10^{-8}$ & $5 \times 10^{-5}$ & $2 \times 10^{-7}$ & $8 \times 10^{-5}$ & $3 \times 10^{-8}$ & $2 \times 10^{-5}$ \\
\hline$\beta$-Endosulfan & 2480 & 7679 & $2 \times 10^{-6}$ & $1 \times 10^{-3}$ & $6 \times 10^{-6}$ & $3 \times 10^{-3}$ & $2 \times 10^{-6}$ & $8 \times 10^{-4}$ & $5 \times 10^{-6}$ & $3 \times 10^{-3}$ & $7 \times 10^{-7}$ & $2 \times 10^{-4}$ & $2 \times 10^{-6}$ & $1 \times 10^{-3}$ \\
\hline Endrin aldehyde & 2861 & 5191 & $2 \times 10^{-6}$ & - & $4 \times 10^{-6}$ & - & $2 \times 10^{-6}$ & - & $4 \times 10^{-6}$ & - & $8 \times 10^{-7}$ & - & $2 \times 10^{-6}$ & - \\
\hline Tebuconazole & 18 & 23 & $2 \times 10^{-8}$ & $5 \times 10^{-7}$ & $2 \times 10^{-8}$ & $6 \times 10^{-7}$ & $1 \times 10^{-8}$ & $4 \times 10^{-7}$ & $2 \times 10^{-8}$ & $5 \times 10^{-7}$ & $5 \times 10^{-9}$ & $2 \times 10^{-7}$ & $7 \times 10^{-9}$ & $2 \times 10^{-7}$ \\
\hline$\lambda$-Cyhalothrin & 30 & 47 & $2 \times 10^{-8}$ & $8 \times 10^{-7}$ & $4 \times 10^{-8}$ & $1 \times 10^{-6}$ & $2 \times 10^{-8}$ & $7 \times 10^{-7}$ & $3 \times 10^{-8}$ & $1 \times 10^{-6}$ & $9 \times 10^{-9}$ & $5 \times 10^{-4}$ & $1 \times 10^{-8}$ & $5 \times 10^{-7}$ \\
\hline Permethrin I & 103 & 319 & $8 \times 10^{-8}$ & $2 \times 10^{-6}$ & $3 \times 10^{-7}$ & $5 \times 10^{-6}$ & $7 \times 10^{-8}$ & $1 \times 10^{-6}$ & $2 \times 10^{-7}$ & $4 \times 10^{-6}$ & $3 \times 10^{-8}$ & $5 \times 10^{-7}$ & $9 \times 10^{-8}$ & $2 \times 10^{-6}$ \\
\hline Permethrin II & 235 & 426 & $1 \times 10^{-7}$ & $4 \times 10^{-6}$ & $3 \times 10^{-7}$ & $7 \times 10^{-6}$ & $2 \times 10^{-7}$ & $3 \times 10^{-6}$ & $3 \times 10^{-7}$ & $6 \times 10^{-6}$ & $7 \times 10^{-8}$ & $1 \times 10^{-6}$ & $1 \times 10^{-7}$ & $2 \times 10^{-6}$ \\
\hline
\end{tabular}

PRB: Piracicaba; SPA: São Paulo; -: compound not detected; 4,4'-DDE: dichloro-diphenyldichloroethylene.

human health by inhalation exposure to these compounds.

Table 2 shows the cancer classification proposed by the EPA, and the results obtained in this study for the maximum values of DIE in adults, children and infants, for PRB and SPA.

Pesticides classified by the EPA as "likely to be carcinogenic to humans" and "possible human carcinogen" are interesting because high concentrations of these

Table 2. Cancer classification and cancer risk for pesticides in Piracicaba (PRB) and São Paulo (SPA)

\begin{tabular}{|c|c|c|c|c|c|c|c|}
\hline \multirow{3}{*}{ Pesticide } & \multirow{3}{*}{ Classification } & \multicolumn{6}{|c|}{ Cancer risk } \\
\hline & & \multicolumn{2}{|c|}{ Infants } & \multicolumn{2}{|c|}{ Children } & \multicolumn{2}{|c|}{ Adults } \\
\hline & & $\mathrm{PRB}$ & SPA & PRB & SPA & PRB & SPA \\
\hline Demeton-o & not carcinogenic ${ }^{\mathrm{a}}$ & $7 \times 10^{-7}$ & $5 \times 10^{-7}$ & $6 \times 10^{-7}$ & $3 \times 10^{-7}$ & $2 \times 10^{-7}$ & $2 \times 10^{-7}$ \\
\hline Diazinon & likely carcinogenic ${ }^{\mathrm{b}}$ & - & $1 \times 10^{-7}$ & - & $1 \times 10^{-7}$ & - & $5 \times 10^{-8}$ \\
\hline Heptachlor & possible $^{\mathrm{c}}$ & $1 \times 10^{-5}$ & $9 \times 10^{-6}$ & $1 \times 10^{-5}$ & $7 \times 10^{-6}$ & $5 \times 10^{-6}$ & $3 \times 10^{-6}$ \\
\hline Malathion & not evidence ${ }^{\mathrm{d}}$ & $1 \times 10^{-7}$ & $9 \times 10^{-7}$ & $1 \times 10^{-7}$ & $7 \times 10^{-7}$ & $5 \times 10^{-8}$ & $3 \times 10^{-7}$ \\
\hline Heptachlor-epoxide & - & $9 \times 10^{-7}$ & $2 \times 10^{-6}$ & $8 \times 10^{-7}$ & $1 \times 10^{-6}$ & $3 \times 10^{-7}$ & $6 \times 10^{-7}$ \\
\hline$\alpha$-Endosulfan & not carcinogenic ${ }^{\mathrm{a}}$ & $7 \times 10^{-7}$ & - & $6 \times 10^{-7}$ & - & $3 \times 10^{-7}$ & - \\
\hline 4,4'-DDE & likely carcinogenic ${ }^{b}$ & - & $5 \times 10^{-8}$ & - & $4 \times 10^{-8}$ & - & $2 \times 10^{-8}$ \\
\hline Ethion & evidence $^{\mathrm{e}}$ & $5 \times 10^{-8}$ & $9 \times 10^{-9}$ & $4 \times 10^{-8}$ & $2 \times 10^{-9}$ & $2 \times 10^{-8}$ & $3 \times 10^{-9}$ \\
\hline$\beta$-Endosulfan & not carcinogenic ${ }^{\mathrm{a}}$ & $2 \times 10^{-7}$ & $6 \times 10^{-7}$ & $2 \times 10^{-7}$ & $5 \times 10^{-7}$ & $7 \times 10^{-8}$ & $2 \times 10^{-7}$ \\
\hline Endrin aldehyde & - & $2 \times 10^{-7}$ & $4 \times 10^{-7}$ & $2 \times 10^{-7}$ & $4 \times 10^{-7}$ & $8 \times 10^{-8}$ & $2 \times 10^{-7}$ \\
\hline Tebuconazole & possible $^{\mathrm{c}}$ & $2 \times 10^{-9}$ & $2 \times 10^{-9}$ & $1 \times 10^{-9}$ & $2 \times 10^{-9}$ & $5 \times 10^{-10}$ & $7 \times 10^{-10}$ \\
\hline$\lambda$-Cyhalothrin & - & $2 \times 10^{-9}$ & $4 \times 10^{-9}$ & $2 \times 10^{-9}$ & $3 \times 10^{-9}$ & $9 \times 10^{-10}$ & $1 \times 10^{-9}$ \\
\hline Permethrin I & likely carcinogenic ${ }^{b}$ & $8 \times 10^{-9}$ & $3 \times 10^{-8}$ & $7 \times 10^{-9}$ & $2 \times 10^{-8}$ & $3 \times 10^{-9}$ & $9 \times 10^{-9}$ \\
\hline Permethrin II & likely carcinogenic ${ }^{\mathrm{b}}$ & $2 \times 10^{-8}$ & $3 \times 10^{-8}$ & $2 \times 10^{-8}$ & $3 \times 10^{-8}$ & $7 \times 10^{-9}$ & $1 \times 10^{-8}$ \\
\hline
\end{tabular}

${ }^{\mathrm{a}}$ Not likely to be carcinogenic to humans; blikely to be carcinogenic to humans; ${ }^{\mathrm{c}}$ possible human carcinogenic; ${ }^{\mathrm{d}}$ suggestive evidence of carcinogenicity, but not sufficient to assess human carcinogenic potential; e evidence of no carcinogenicity for humans. ${ }^{30}-$ : compound not detected; 4,4 '-DDE: dichlorodiphenyldichloroethylene. The cancer risk was calculated for the compounds with the highest detection frequency. 
compounds increase the risk of cancer in the population. ${ }^{30}$ The maximum value acceptable for the cancer risk is $1 \times 10^{-6} \cdot{ }^{26}$ Higher values can be interpreted as excess cancer risk for a given population.

For the compounds classified as: likely carcinogenic, possible carcinogenic, no evidence and evidence of carcinogenicity, the highest values observed in infants, children and adults, respectively, for heptachlor were: $1 \times 10^{-5}, 1 \times 10^{-5}$ and $5 \times 10^{-6}$ at PRB, and $9 \times 10^{-6}, 7 \times 10^{-6}$ and $3 \times 10^{-6}$ at SPA. These values exceeded the maximum allowable value, indicating cancer risk for these populations at both sampling sites. Another pesticide, which exceeded this limit, was heptachlor epoxide, in infants and children at SPA site. As mentioned above, the carcinogenic activity for this compound was not reported (Table 2).

\section{Conclusions}

In this work, the concentration of pesticides in the atmosphere of São Paulo and Piracicaba cities (sugarcane plantation site) was determined and the hazard quotients and cancer risk caused by inhalation of these compounds were calculated. Twenty-three samples were analyzed, and 34 pesticides associated to atmospheric particulate matter $\left(\mathrm{PM}_{2.5}\right.$ and $\left.\mathrm{PM}_{10}\right)$ were investigated by GC-MS. Fourteen compounds including organochlorines, organophosphorus and pyrethroids pesticides, were found in these samples. Among them, heptachlor and ethion were found in all samples collected in Piracicaba and permethrin I and II in São Paulo, as well.

The values for DIE were calculated for infants, children and adults and they do not suggest inhalation hazard, i.e., respiratory problems, for this population. Despite this, heptachlor, compound classified as possible carcinogenic for humans, presented high cancer risk values for all population, suggesting that the exposure to this compound can be dangerous.

This work could be a good contribution to better understand the role of pesticides associated to inhalable atmospheric particulate matter, and the hazard quotients and cancer risk caused by inhalation of these compounds.

\section{Supplementary Information}

Supplementary data are available free of charge at http://jbcs.sbq.org.br as PDF file.

\section{Acknowledgments}

The authors thank CNPq (projects 465497/2014-4, 133711/2017-0), CAPES (project 88887.136374/2017-00),
FAPESB (projects 8164/2014 and 2159/2012), Financiadora de Projetos e Estudos (01.14.0215.00) and FAPESP (project 2017/20826-1). J. B. A., G. O. R. and P. C. V. thank CNPq for their research fellowships.

\section{References}

1. Coscollà, C.; Yusà, V.; Comprehensive Analytical Chemistry, vol. 73.; Elsevier: London, UK, 2016.

2. Villiot, A.; Chrétien, E.; Drab-Sommesous, E.; Rivière, E.; Chakir, A.; Roth, E.; Atmos. Environ. 2018, 174, 82.

3. Viel, J. F.; Floret, N.; Deconinck, E.; Focant, J. F.; De Pauw, E.; Cahn, J. Y.; Environ. Int. 2011, 37, 449.

4. Casida, J. E.; Durkin, K. A.; Annu. Rev. Entomol. 2013, 58, 99.

5. ht t p : / portal.anvis a.gov.br/registros-eautorizacoes/agrotoxicos/produtos/monografiade-agrotoxicos/autorizadas, accessed in January 2020.

6. http://revistapesquisa.fapesp.br/wp-content/ uploads/2018/09/018-027_CAPA-Agrotóxicos_271.pdf, accessed in January 2020.

7. Bombardi, L. M.; Geografia de Uso de Agrotóxicos no Brasil e Conexões com a União Europeia, vol. 1, $1^{\text {st }}$ ed.; USP: São Paulo, Brazil, 2017.

8. https://cidades.ibge.gov.br/brasil/sp/piracicaba/panorama, accessed on April 24, 2019.

9. https://cidades.ibge.gov.br/brasil/sp/sao-paulo/panorama, accessed on April 24, 2019.

10. http://agrofit.agricultura.gov.br/agrofit_cons/principal_agrofit_ cons, accessed in January 2020.

11. http://www.leb.esalq.usp.br/leb/exceldados/DCE2008.TXT, accessed in January 2020.

12. http://www.estacao.iag.usp.br/Boletins/2017.pdf, accessed in January 2020.

13. Nascimento, M. M.; da Rocha, G. O.; de Andrade, J. B.; Microchem. J. 2018, 139, 424.

14. European Commission (EC); SANCO/12571/2013: Guidance Document on Analytical Quality Control and Validation Procedures for Pesticides Residues Analysis in Food and Feed; European Commission Health \& Consumer Protection Directorate-General and Safety of the Food Chain Chemicals, Contaminants, and Pesticides, 2013; available at http:// www.eurl-pesticides.eu/library/docs/allcrl/AqcGuidance_ Sanco_2013_12571.pdf, accessed in January 2020.

15. EPA; Guidelines for Carcinogen Risk Assessment; 2005, available at https://www.epa.gov/sites/production/files/2013-09/ documents/cancer_guidelines_final_3-25-05.pdf, accessed in January 2020.

16. Lee, S.; McLaughlin, R.; Harnly, M.; Gunier, R.; Kreutzer, R.; Environ. Health Perspect. 2002, 110, 1175.

17. Harner, T.; Bidleman, T. F.; Environ. Sci. Technol. 1998, 32, 1494. 
18. https://sitem.herts.ac.uk/aeru/iupac/Reports/78.htm, accessed in January 2020.

19. Hart, E.; Coscollà, C.; Pastor, A.; Yusà, V.; Atmos. Environ. 2012, 62, 118.

20. Weber, J.; Halsall, C. J.; Muir, D.; Teixeira, C.; Small, J.; Solomon, K.; Hermanson, M.; Hung, H.; Bidleman, T.; Sci. Total Environ. 2010, 408, 2966.

21. Chrysikou, L. P.; Gemenetzis, P. G.; Samara, C. A.; Atmos. Environ. 2009, 43, 290.

22. Coscollà, C.; López, A.; Yahyaoui, A.; Colin, P.; Robin, C.; Poinsignon, Q.; Yusà, V.; Sci. Total Environ. 2017, 584-585, 856.

23. Meire, R. O.; Khairy, M.; Targino, A. C.; Galvão, P. M. A.; Torres, J. P. M.; Malm, O.; Lohmann, R.; Chemosphere 2016, $144,2175$.

24. Wang, W.; Wang, Y.; Zhang, R.; Wang, S.; Wei, C.; Chaemfa, C.; Li, J.; Zhang, G.; Yu, K.; Sci. Total Environ. 2016, 542, 777.

25. http://acpo.org.br/paulinia/paulinia.pdf, accessed in January 2020.
26. Yusà, V.; Coscollà, C.; Millet, M.; Atmos. Environ. 2014, 96, 322.

27. Vasconcellos, P. C.; Souza, D. Z.; Sanchez-Ccoyllo, O.; Bustillos, J. O.; Lee, H.; Santos, F. C.; Nascimento, K. H.; Araújo, M. P.; Saarnio, K.; Teinilä, K.; Hillamo, R.; Sci. Total Environ. 2010, 408, 5836.

28. Gevao, B.; Porcelli, M.; Rajagopalan, S.; Krishnan, D.; Martinez-Guijarro, K.; Alshemmari, H.; Bahloul, M.; Zafar, J.; Sci. Total Environ. 2018, 622-623, 1621.

29. López, A.; Yusà, V.; Muñoz, A.; Vera, T.; Borràs, E.; Ródenas, M.; Coscollà, C.; Sci. Total Environ. 2017, 574, 724.

30. http://npic.orst.edu/chemicals_evaluated.pdf, accessed in January 2020.

Submitted: October 30, 2019 Published online: February 3, 2020 